\title{
1 Forest disturbance and regeneration: a mosaic of discrete gap dynamics and open \\ 2 matrix regimes?
}

3 George Alan Blackburn, Zulkiflee Abd Latif \& Doreen Sandra Boyd

5 Blackburn, G.A. (corresponding author, alan.blackburn@lancaster.ac.uk): Lancaster Environment

6 Centre, Lancaster University, Lancaster, LA1 4YQ, UK

7 Abd Latif, Z. (zulki721@salam.uitm.edu.my): Centre for Geospatial Technology, Faculty of Architecture,

8 Planning \& Surveying, Universiti Teknologi MARA, 40450 Shah Alam, Selangor, Malaysia

9 Doreen Sandra Boyd (doreen.boyd@nottingham.ac.uk): School of Geography, The University of

10 Nottingham, University Park, Nottingham, NG7 2RD,UK

12 Abstract

13 Question: Recent research in boreal forest suggests that an 'open matrix' model may be more

14 appropriate than the traditional model of spatially discrete gap dynamics for describing forest disturbance

15 and regeneration but what is the evidence from temperate broadleaved deciduous forests concerning the

16 prevalence of these alternative models?

17 Location: Semi-natural temperate broadleaved deciduous forest in southern England.

18 Methods: Multi-temporal LiDAR data were used to monitor the changes in tree canopy height and 19 canopy gaps over a 10 year period for a 130ha area of forest. Gap dynamics were characterised by 20 quantifying gap creation, expansion, contraction and closure. By identifying the types and rates of canopy

21 height transitions, areas of gap contraction and closure were attributed to the processes of lateral crown 22 growth or vertical regeneration.

23 Results: Across the study site there was a zonation in canopy and gap properties and their dynamics.

24 Many areas of the forest had the characteristics of open wood-pasture dominated by large, complex gaps

25 being maintained under a regime of chronic disturbance. In these areas, several characteristics of the gap

26 dynamics indicated that regeneration was restricted and this may be attributable to spatially-focussed

27 overgrazing by large herbivores. In contrast, other areas were characterised by high, closed canopy forest 28 with small, discrete gaps where gap creation and infill were balanced. 
Conclusions: At the landscape-scale broadleaved deciduous forests contain a spatial mosaic of zones which conform to different models of disturbance and regeneration dynamics; discrete gap dynamics and open matrix regimes are juxtaposed. It is now important to elucidate the abiotic factors and biotic interactions which determine the spatio-temporal distribution of the different regimes and to examine whether such a 'regime mosaic' model is applicable in other forest types.

Keywords: Disturbance; Regeneration; Gap dynamics; Broadleaved Deciduous Forest; LiDAR.

Running head: A mosaic of disturbance and regeneration regimes

\section{Introduction}

The storm gap theory of forest dynamics was originated by Sernander (1936) based on observations of the loss of canopy trees during storm events which created sites where a systematic process of regeneration led to the restoration of a closed canopy. Subsequent research has refined the theory and demonstrated that gap creation affects canopy structure and the spatio-temporal properties of forest communities (White 1979; Pickett and White 1985). It is now recognised that canopy gaps can be caused by various factors, including meteorological vectors, insects, disease and the death of individual or multiple trees (McCarthy 2001). Subsequently, gaps can be filled by tree regeneration or lateral crown growth and the resulting canopy is then subject to further gap creation mechanisms; this entire cyclic process is termed gap dynamics (Brokaw \& Busing 2000). The importance of gap dynamics in controlling a wide range of ecosystem properties and processes has been well documented for temperate broadleaved (Runkle 1982; Veblen 1989; Stewart et al. 1991; Ritter et al. 2005; Abd Latif \& Blackburn 2010), temperate coniferous

51 (Spies et al. 1990; Muscolo et al. 2007; Kathke \& Bruelheide 2010), boreal (Fraver et al. 2008; Liu \&

52 Hytteborn 1991; Ulanova 1991 \& 2000) and tropical forests (Brokaw 1985; Van Dam 2001; Marthews et 53 al. 2008; Gravel et al. 2010).

It has been demonstrated that various properties of gaps can influence species composition and

55 forest structure via their effects within the open and growth phases of the forest cycle (Denslow \& Spies 56 1990; Elias \& Dias 2009). In particular, it has been shown that the recruitment and establishment of tree

57 species is a function of gap size, gap shape, gap age, number and causes of treefalls and canopy height

58 (Barik et al. 1992; Arriaga 2000; Schnitzer \& Carson 2001; Li et al. 2005; Lima \& Moura 2008; Sapkota 
\& Oden 2009). Hence, it has been suggested that quantifying gap characteristics is essential for understanding disturbance and regeneration dynamics and the consequent impact on ecological processes (Gagnon et al. 2004).

In temperate broadleaved deciduous forests, which are the focus of the present study, it has been recognised that the role of gap characteristics in the recruitment and regeneration of tree species is still not fully understood (Yang et al. 2009). Nevertheless, several studies have demonstrated the importance of a range of gap properties in maintaining the diversity and regeneration of species within broadleaved deciduous forests spanning the temperate zone in the northern hemisphere (Vetaas 1997; Li et al. 2005; Ritter et al. 2005; Zang et al. 2005). Research has shown that gap size, shape and orientation (Dahir \& Lorimer 1996), characteristics of gap creating species (Boettcher \& Kalisz 1990) and the understorey species surviving in gaps (Taylor \& Qin 1988) affect microclimate, species recruitment and regeneration rate in broadleaved deciduous forest.

The storm gap theory which forms the basis of our understanding of gap dynamics implies that gaps are spatially discrete units that can be readily distinguished from surrounding closed canopy and that gaps undergo directional development in composition and structure over time. Here we define this as the spatially discrete model of gap dynamics, which results in a forest that can be described as a mosaic of spatial units that are at different stages of the directional process of regeneration or infill following different disturbance events. However, this model could be disputed on the basis of whether gaps can be defined as spatially discrete units and whether the compositional and structural development within gaps is directional and largely dependent upon the properties of the gap itself rather than surrounding components of the forest. Indeed, the literature reveals that there is a wide variety of ways of defining and measuring gaps (see review by Schliemann \& Bockheim 2011): some use simple thresholds in height difference between surrounding canopy and gap vegetation to characterise the 'hole' in the canopy (e.g. Brokaw 1982); others use more complex models of gap geometry (e.g. Ferreira de Lima 2005); while some emphasise the area which is influenced by the canopy opening (e.g. Porma et al. 1989). Furthermore, some researchers have questioned the entire notion of the canopy gap as a spatially discrete entity, indicating that the transition between gap and closed canopy is characterised by a continuum of change in environmental conditions (Lieberman et al., 1989).

Recently, Hytteborn \& Verwijst (2014) argued that an 'open matrix' model may be more appropriate than the spatially discrete model of gap dynamics for describing forest disturbance and regeneration. Using evidence from three resurveyed plots in a boreo-nemoral forest, they found that the forest became dominated by an open tree matrix which had a low tree density and gaps were interconnected because gap creation rate was higher than closure rate. They observed that initial gaps may partly close or merge into larger gaps and as a consequence the compositional and structural development 
within a gap is not directional and cannot be predicted from the initial characteristics of the gap.

94 Consequently, rather than describing the dynamics of spatially discrete gaps within a surrounding closed canopy, the open matrix model explains how the fate of a single gap or canopy area depends upon the development of neighbouring gaps or canopy areas. Hytteborn \& Verwijst (2014) suggest that the open matrix model may be applicable across the full range of forest types, from boreal to tropical rainforest. Hence, the present study aimed to investigate whether discrete gap dynamics or the open matrix model provides suitable descriptions of disturbance and regeneration using evidence from temperate broadleaved deciduous forests.

Our overall approach was to map the distribution of tree canopy and gaps at the study site on two occasions and determine the extent to which (i) initial gap areas remain as discrete spatial units and undergo directional regeneration or lateral infill (supporting the spatially discrete model of gap dynamics) or (ii) initial gap areas are spatially modified due to changes in adjacent canopy and gap areas and fail to experience directional regeneration or lateral infill (supporting the open matrix model). As it can be difficult to obtain information on forest disturbance and regeneration over appropriate spatial and temporal scales, a key objective of this study was to establish a suitable a method to quantify gap dynamics in temperate broadleaved deciduous forests. Our technique involved the novel use of multitemporal remotely-sensed data and the methodological developments which permitted this are outlined in this paper, along with the insights into forest disturbance and regeneration that were generated by this

\section{Methods}

\section{Study site}

115 The location for this research was Frame Wood and the adjoining Tantany Wood in the New Forest, 116 southern England $\left(1^{\circ} 30^{\prime} \mathrm{W}, 50^{\circ} 50^{\prime} \mathrm{W}\right)$. The New Forest is recognised as being of international

117 importance to nature conservation; it is mostly Crown property and managed by the Forestry

118 Commission. The study site is an unenclosed forest which is permanently open to grazing by the ponies 119 and cattle of the Commoners and wild deer. There are 4049 ha of unenclosed forests in the New Forest, in 120 total. Within the study site the dominant tree species are Quercus robur and Quercus petraea, Fagus

121 sylvatica, Betula pendula and Betula pubescens. Historically there have been several periods of selective

122 felling in Frame Wood and Tantany Wood. However, these stands are among the closest to 'old-growth'

123 primary forests that exist in the UK, and among the standing trees, several generations have been

124 identified with some individuals aged over 500 years (Flower 1977; Tubbs 1986). Gap vegetation consists 
predominantly of Pteridium aquilinum and grasses that have been maintained by grazing pressure to form a low, tight sward. Canopy gaps have mostly been created by natural treefalls, as result of tree death, disease and windthrow (Morgan 1987; Koukoulas \& Blackburn 2005). In the New Forest Act 1877 the term 'Ancient and Ornamental Woodlands' was used to define this forest type which is widely distributed throughout the area (Forestry Commission 2008).

\section{Choice of methods for quantifying disturbance and regeneration dynamics}

Disturbance and regeneration dynamics can only be quantified by analysing multi-temporal data, however, it has been noted that this can be difficult due to changes over time in gap and canopy definitions used, the accuracy of gap delineation and the methods employed for quantifying forest structure (Barden 1989). Moreover, measurement of forest disturbance and regeneration in the field is complex, costly, time consuming and limited to small spatial extents (Hu et al. 2009).

The synoptic view of remote sensing has the potential to provide a standardized approach for characterizing forest gap and canopy properties with high spatial and temporal resolution and comprehensive spatial coverage. Passive optical remote sensing has shown some promise in this respect (Blackburn \& Milton 1996, 1997; Tanaka \& Nakashizuka 1997), and, in particular, the availability of extended time series aerial photography has enabled the analysis of repeated gap formation events (Torimaru et al. 2012). However, there are some limitations in identifying canopy gaps in passive optical imagery due to shadowing effects and spectral inseparability leading to inaccurate canopy height estimations especially in closed forests (St-Onge et al. 2004). LiDAR data has been widely used in forestry and ecological studies (Hyde et al. 2006; Falkowski et al. 2009) and specifically, in several studies of canopy gaps (Koukoulas \& Blackburn 2004; Yu et al. 2004, Boyd et al. 2013), canopy height and forest structure (Lefsky et al. 2002; Naessat 2004; St-Onge et al. 2004) and for creating accurate digital terrain models (DTM's) (Krauss \& Pfeiffer 1998; Hodgson et al. 2003; Clark et al. 2004). Thus, multi-temporal LiDAR appears to be an appropriate tool for assessing forest disturbance and regeneration. Indeed, Vepakomma et al. $(2008,2011)$ recently established that multi-temporal LiDAR can be used to spatially characterise canopy gap dynamics in boreal forests. Gap creation at the site used in that study was mainly due to fire and spruce budworm outbreaks. An object-based technique was applied to small footprint LiDAR data to map canopy gaps of sizes ranging from a few square meters to several hectares. Gap dynamics over a five year period were quantified using LiDAR-derived canopy height models (CHMs) and this work indicates that there is considerable potential for developing LiDAR-based approaches for monitoring gap dynamics in other forest types. Hence, the present study used multitemporal LiDAR data for mapping the changes in gap and canopy properties, in a temperate broadleaved deciduous forest. 


\section{LiDAR data acquisition and registration}

159

160

161

162

163

164

165

166

167

168

169

170

171

172

173

174

175

176

177

178

179

180

181

182

183

184

185

186

187

188

189

LiDAR data were acquired in July 1997 and again in July 2007. The 1997 LiDAR data acquisition was carried out by UK Environment Agency (EA) using an Airborne Laser Terrain Mapping (ALTM) 1020 (Optech, Canada). The 2007 LiDAR data was acquired by the UK Natural Environment Research Council Airborne Research and Survey Facility (NERC ARSF) using an ALTM 3033 system (Optech, Canada). Both systems recorded single (first) returns only. Table 1 presents the key survey and LiDAR instrument parameters. While flight altitude differences were compensated for by the beam divergence differences, leading to approximately equal footprint sizes, the differences in pulse frequency lead to a notable difference in point density. Such differences are inevitable when using different generations of LiDAR instruments and our method for accounting for this disparity is discussed later. The 2007 data were used to generate a digital terrain model (DTM) because they were of higher point density and were collected using the NERC ARSF aircraft which had a more sophisticated inertial navigation system and higher rate GPS which, combined with post-processing using differential correction using GPS base station data, produces accurate elevations (NERC ARSF 2012). The 2007 point cloud was classified into ground and non-ground returns and the former were interpolated to a raster grid, to generate a DTM with a resolution of $1 \mathrm{~m}$. A differential GPS survey at 90 control points revealed levels of accuracy in elevation for the DTM $($ RMSE $=0.45 \mathrm{~m})$ comparable with previous studies (e.g. Hodgson \& Bresnahan 2004) and this was considered acceptable for the present investigation.

[TABLE 1]

Digital surface models (DSM) were generated by interpolating the 1997 and 2007 LiDAR data to raster grids with a $1 \mathrm{~m}$ resolution. An inverse distance weighted algorithm was used for interpolation as it was previously found optimal for generating elevation models and minimising errors due to point density differences in multi-temporal LiDAR data (Vepakomma et al. 2008). The pre-processing routines of both EA and NERC ARSF, using inertial navigation and kinematic GPS data, ensured that both datasets were georeferenced and this was confirmed by overlaying and visually comparing a vector map (from the UK Ordnance Survey) of the major infrastructural features of the study site (e.g. roads, railways, tracks and forest compartments) with the two DSM's. This revealed that the 1997 DSM had a small planimetric offset (typically in the order of 1-2 pixels) from the 2007 and OS data, which were in agreement. This offset may have resulted from factors such as the differences in pre-processing routines for the two data sets or variability in atmospheric conditions or GPS configuration during acquisition (Katzenbeisser 2003). Therefore, using ground control points distributed across the study site, the 1997 DSM was registered with the 2007 DSM using a second order polynomial transformation. Then to examine the 
correspondence in elevation values between the two DSMs, 50 bare ground locations across the study site were selected using the vector data for infrastructure such as forest tracks, with manual verification that these were bare surfaces, using a subset of locations. At the bare ground locations, elevation values were extracted from each of the DSMs and this revealed that there were no systematic offsets, with good overall agreement $(\mathrm{RMSE}=0.26 \mathrm{~m})$ between the DSMs. Therefore, the DTM was subtracted from the DSMs from each year in order to derive two CHM's for the study site (Figure 1).

\section{[FIGURE 1]}

\section{Gap delineation}

In this study, gaps were considered as canopy openings and areas of low vegetation caused by single and multiple treefalls. Hence, a minimum size threshold for a single treefall of $30 \mathrm{~m}^{2}$ was used to identify gaps for subsequent analysis and a height of $4 \mathrm{~m}$ was used as the threshold for distinguishing gaps from canopy areas using the CHM. These thresholds were determined from previous work at the study site (Koukoulas \& Blackburn 2004, 2005) and confirmed through further field verification undertaken as part of the present study. Consequently it was possible to implement a simple procedure for generating gap maps, by applying a threshold of 4m to the CHM's, above which areas were identified as canopy and below as gaps. The resulting binary map was filtered to remove any gap areas smaller than $30 \mathrm{~m}^{2}$. This procedure was validated by comparing 40 gaps extracted from the 2007 CHM with the same gaps digitised manually from digital colour aerial photographs $(10 \mathrm{~cm}$ spatial resolution) that were acquired concurrently with the LiDAR data. The sample of gaps was selected to cover a wide range of gap shapes and sizes (area range 42 to $460 \mathrm{~m}^{2}$ ). The results showed a good agreement between the two methods, with an RMSE value of $7.3 \mathrm{~m}^{2}$ (mean error $=3.2 \%$ ) for area, which compares favourably with the variability in gap size when estimated using different field-based manual survey methods (Ferreira de Lima 2005) and is comparable with ground-based remote sensing methods (Hu et al. 2009). It is worth noting that using the LiDAR technique, dead standing trees would not be identified as gaps until the remaining woody structures had deteriorated to such an extent that the LiDAR returns from that area generated a CHM of less than 4m height over a $30 \mathrm{~m}^{2}$ contiguous area. The LiDAR technique was not able to directly determine the mechanisms which initiated or maintained gaps, therefore other lines of evidence were used to infer such mechanisms.

Given that the 1997 LiDAR data was of a lower point density, it was important to examine whether the technique for delineating gaps (outlined above) was valid for the 1997 data. As there was no concomitant aerial photography for 1997 a direct validation was not possible. Furthermore, because of the likely changes in canopy height and spatial structure, it was inappropriate to directly compare the CHMs 
[FIGURE 2]

\section{Characteristics of gap dynamics} more complex.

form 1997 and 2007. Therefore, characteristics of the 1997 data were simulated by spatially thinning the 2007 point cloud to generate a new point cloud with the same average point density as that of the 1997 data (i.e. 0.3 hits $/ \mathrm{m}^{2}$ ). The new point cloud was then interpolated to generate a DSM; the DTM was subtracted to generate a new CHM. The original 2007 CHM and the new CHM (reduced point density) were compared statistically and this revealed that overall, there was a high degree of correlation $(\mathrm{R}=0.95$, sig.99\%c.i.) with insignificant offset and bias. This minimal impact of reduced point density on canopy height estimates has been observed in other empirical and modelling studies (Goodwin et al. 2006; Disney et al. 2010). When the $4 \mathrm{~m}$ threshold was applied to the new CHM, this was found to underestimate the total gap area across the study site by a small amount (1\%). However, as observed by Vepakomma et al. (2011), such underestimation affects smaller gaps proportionally greater than large gaps (here typically $10 \%$ for a gap of $40 \mathrm{~m}^{2}$ ), and the underestimation may also lead to the artificial separation of gaps that are connected by narrow corridors. Hence, it was felt that further analysis was needed to fully account for the effects of differences in point density of the two LiDAR data sets.

By examining the two CHM's together with height transects across gap zones and the gap delineations resulting from application of the $4 \mathrm{~m}$ threshold, it was found that at the edge of gaps there was typically a rapid decrease in height over the transition from tree canopy to gap in the original 2007 CHM, whereas in the reduced point density CHM the rate of decrease in height was lower. This indicated that the higher point density data was able to provide a better representation of the full extent of tree crowns that surrounded gaps. In testing various methods to account for this, it was found that a simple and effective technique was to adjust the height threshold used for gap delineation. By iteratively adjusting the threshold and observing the change on gap area delineated, it was found that an optimum threshold of $4.059 \mathrm{~m}$ generated the equivalent gap area when applied to the reduced point density CHM as compared to the $4 \mathrm{~m}$ threshold applied to the original CHM (Figure 2). Hence, this optimised threshold for reduced point density was applied to the CHM generated from the 1997 LiDAR data to generate a binary gap and canopy map. Using the 1997 and 2007 gap and canopy maps, the area and perimeter of each gap was determined and gap shape was quantified using the perimeter to area ratio (P:A). Several workers, such as Battles et al. (1996) have identified the P:A ratio as a useful indicator for assessing the irregularity of canopy openings. A circular gap will have the lowest P:A and as P:A increases the shape of gaps becomes 
The multi-temporal LiDAR data were used to determine important characteristics that describe the processes involved in gap dynamics. Within the study area, the characteristics defined were areas of canopy openings (new gaps or gap expansions), gap closures (due to regeneration or lateral crown expansion), gap contractions (due to regeneration or lateral crown expansion) and continuous gaps, using a similar technique to that of Vepakomma et al. (2008). A transect running through the 1997 and 2007 CHM's demonstrates the various forms of gap and canopy change (Figure 3). A new gap is defined as a gap in the canopy that is present in 2007 but not in 1997 (A). A gap expansion is when a gap existing in 1997 becomes enlarged in 2007 (B). Regeneration is where a gap area is lost because there is an increase of vegetation height from beneath $4 \mathrm{~m}$ in 1997 to over $4 \mathrm{~m}$ in 2007, but the increment in height is less than $6 \mathrm{~m}$ (n.b. the paragraph below explains how the value of $6 \mathrm{~m}$ was derived) (C). Lateral expansion of tree crowns at the gap edge is identified by an increment in height of more than $6 \mathrm{~m}$ (i.e. a height increase that is greater than that which is possible by growth of regenerating trees within gaps) (D). It is possible for regeneration or lateral crown expansion to result in either the complete closure of a gap that existed in 1997 or a contraction of part of the gap area that existed in 1997. Continuous gap areas are present consistently in 1997 and 2007 (E).

[FIGURE 3]

Using the differences between the CHM's from 1997 and 2007 it was possible to distinguish gap areas that have filled due to regeneration (i.e. due to vertical growth of young trees within gaps) and from

271 lateral canopy expansion (predominantly horizontal growth of mature crowns). The method used here was

272 to define a threshold for the increment in canopy height, below which the increase in height would be

273 within the range possible given the growth rate of broadleaved deciduous trees; above which the increase

274 in canopy height could only be explained by the lateral expansion of mature crowns. Higo et al. (1992)

275 reported that the maximum growth rate of broadleaved deciduous trees in temperate regions was

276 approximately $0.51 \mathrm{~m}$.year ${ }^{-1}$. Thus, we might expect a maximum increment in canopy height of between 5

277 to $6 \mathrm{~m}$ over the ten year period of the present study. In order to confirm whether this was an appropriate 278 threshold, a histogram showing the difference between the CHM's from 1997 and 2007 was plotted 279 (Figure 4). The Jenks natural breaks classification algorithm was used to identify the 6m break point in 280 the distribution of canopy height increments (as highlighted on the histogram). Hence, given the evidence 281 from the literature concerning maximum growth rates and the break point in the histogram, a height 282 increment of $6 \mathrm{~m}$ was identified as a threshold for separating gap areas that have filled due to regeneration and lateral canopy expansion.

284 [FIGURE 4] 
Results

\section{Gap characteristics}

288

Definable canopy gaps present in 1997 and 2007 are shown in Figure 5. Table 2 summarises the changes that have taken place in the gap and canopy properties across the study site as a whole. The maximum canopy height increased slightly, however there were more extensive changes in gap properties. There was an increase in number of gaps and total gap area, and, accordingly, the proportion of canopy coverage decreased. Similarly the mean gap area increased, particularly because there were several cases where a number of smaller gaps expanded and coalesced to form considerably larger gaps. Hence, the mean gap perimeter increased but the P:A ratio changed little, and the complex shape of gaps was maintained.

[FIGURE 5]

[TABLE 2]

\section{Gap dynamics}

Figure 6 is a spatial representation of the gap and canopy changes that have taken place over the ten year period. In addition to continuing gap areas, the upper map shows areas of gap expansion and entirely new gaps that were created between 1997 and 2007. The lower map shows the areas of gaps present in 1997 that have contracted by 2007 and entire individual gaps that were closed over the study period. Table 3 summarises the area and number of gaps involved in various types of change during the study period. The results demonstrate that the total gap area created was considerably higher than total gap area lost over the study period. The gains in gap area mainly resulted from the expansion of existing gap areas and most gaps (86\%) showed some areas of expansion, resulting from the loss of whole trees or branches at the periphery of gaps. A considerable number of entirely new gaps were created; these were distributed throughout the study site and ranged in area corresponding with the loss of individual and multiple trees. In contrast, a smaller number of gaps were completely closed during the study period and this covered less than half the area of new gaps. Most of the gaps present in 1997 (81\%) showed some areas of contraction, but the dominant process was that of gap expansion. This is because it was possible for any individual gap to have areas of expansion and contraction and a greater proportion of gaps showed more expansion than contraction. This is revealed by the finding that of the gaps present in 1997, 221 had a net decrease in area, 23 no change and 528 had net increase in area. This process of expansion has created areas in the northern and south western parts of the study site that have developed an open wood pasture 
structure (Forestry Commission 2009), with similar proportions of gap and canopy areal coverage. However, there are extensive areas in the central to eastern parts of the study area that are dominated by high (see Figure 1), closed canopy, where there are fewer continuing gap areas and gap dynamics are dominated by the creation and closure of individual gaps with a size corresponding to that of individual trees (see Figure 6).

\section{[FIGURE 6]}

\section{[TABLE 3]}

Figure 7 represents gap areas that have contracted due to regeneration and lateral crown expansion. Lateral crown expansions were generally located along the edges of continuing gaps while regeneration mostly occurred within gaps away from the periphery, where maximum light levels were available for promoting the growth of young trees. However, some regeneration occurred along the periphery of continuing gaps. As Table 3 shows, a greater proportion of the contraction of existing gaps was due to lateral crown expansion than regeneration. Table 3 also demonstrates that of the small proportion of the total gap area lost due to entire gap closure, lateral crown expansion and regeneration were equally responsible for this closure, with most gaps closing due to a combination of both processes. Only 9 of the 133 gap closures were entirely due to lateral crown expansion and 17 entirely due to regeneration.

\section{[FIGURE 7]}

\section{Discussion}

The purpose of this study was to understand the spatio-temporal characteristics of disturbance and regeneration in broadleaved deciduous forests and thereby evaluate the applicability of alternative conceptual models of these processes which have been developed in different forest types. In this respect it is useful to provide some context for the present findings, by comparing our observations of gap dynamics in broadleaved deciduous forests with those found in boreal forests. In the broadleaved deciduous forest gaps tended to be larger than those in the boreal forest found in the recent study by Vepakomma et al. (2008). In the present study $45 \%$ of gaps had an area of $100 \mathrm{~m}^{2}$ or less, whereas in the boreal forest $85 \%$ of gaps were $100 \mathrm{~m}^{2}$ or less. These differences may be attributable to differences in the size of individual tree crowns and the nature of gap creation and regeneration or infilling. Almost all gaps in the broadleaved deciduous forest experienced some contraction due to combined lateral crown 
expansion and regeneration, whereas in the boreal forest only around half of the gaps experienced contraction or closure. This may be because of the larger size of gaps and lower ratio of canopy height to gap diameter generating increased light levels within gaps in the broadleaved deciduous forest, providing greater opportunities for both crown expansion and regeneration (Canham et al. 1990). However, it might be argued that such differences could also result from the longer time period over which the present study monitored gap and canopy changes (compared to the 5-year sampling period of Vepakomma et al. 2008) and the variation in growth rates between the two biomes. Nevertheless, the long term investigation by Hytteborn and Verwijst (2014) confirmed that in boreal forest gaps tended to be smaller than those of the broadleaved deciduous forest and that gaps which did experience total or partial infilling were significantly larger than those not experiencing infill. Hytteborn and Verwijst (2014) noted that the dominant coniferous trees of boreal forest have very slow rates of lateral growth or lack the capacity entirely. This evidence therefore starts to suggest that there may be fundamental differences between broadleaved deciduous and boreal forests in terms of the disturbance and regeneration regimes. However, other information highlights the similarities.

The key process that has been recorded in this study is that of the expansion of existing gaps, which is much greater than new gap creation or gap loss. This has resulted in many areas of the forest being dominated by many large, complex gaps which develop by progressive enlargement of existing gaps, rather than rare large-scale disturbances such as windthrow which usually results in gaps with a simple shape (Franklin et al. 1987). Therefore the large, complex gaps could be considered as 'chronic disturbance patches' (Forman \& Godron 1986), whereby once a gap is created, it is perpetuated by grazing which restricts regeneration (discussed in following paragraph) and repeated disturbance around gap edges. In the present study it was found that most large gaps experienced some regeneration around the periphery and evidence for the suitability of gap edges for regeneration has been found in previous field-based investigations in broadleaved deciduous forests (Canham 1988; Mountford et al. 2006). However, the results show that gap edges are also susceptible to disturbance, resulting in the loss of major branches or entire tree crowns. Recent work by Torimaru et al. (2012) using a time series of aerial photography observed cycles of crown expansion followed by branch or crown loss at gap edges and this supports the concept of gaps in temperate broadleaved forest being maintained by chronic disturbance. As both regeneration and branch or crown loss is taking place at gap edges then the shape of gaps is modified and any change in total area of each gap will be determined by the relative magnitude of regeneration and crown reduction. Such changes can mean that effectively the location of a gap may move overtime and adjacent gaps may join, as found at the present study site. These observations are consistent with the open matrix model proposed by Hytteborn \& Verwijst (2014) in boreal forests, whereby gap expansion and 
coalescence results in a forest consisting of an open tree matrix rather than discrete gaps within a closed canopy.

A series of observations indicate that regeneration is failing across many areas of the study site: the total gap area gained was $41 \%$ greater than the gap area lost; the number and area of new gaps created was greater than gaps closures, by $79 \%$ and $120 \%$, respectively; and where gaps contracted the process of lateral crown expansion was responsible for a much greater proportion of the area of contraction (61\%) than the process of regeneration (39\%). A field-based investigation at a nearby site has indicated that reduced regeneration rates in the unenclosed woodlands of the New Forest are likely due to overgrazing by large herbivores (ponies, deer, cattle) (Mountford and Peterken 2003). That study compared vegetation along transects in areas where herbivores were present and had been excluded and investigated changes over a 40 year period. While the present study covers a shorter period of time, it is spatially comprehensive and provides canopy structural evidence that is complementary to the field data and confirms the limited regeneration in many areas of the study site. There is recent evidence that in temperate broadleaved deciduous forests where grazing by large herbivores has restricted regeneration, removal of the herbivores can promote recovery but this is a slow process and is dependent upon adequate seed sources to ensure full tree canopy regeneration (Tanentzap et al. 2011). However, there is evidence that even before the onset of human impacts across the landscapes of lowland Europe the primary forests were strongly influenced by grazing. While the longer established 'high-forest' hypothesis suggests that the primary forest was dominated by a high, closed canopy of mixed deciduous species (Bradshaw et al. 2003; Mitchell 2005) the more recent 'wood-pasture' hypothesis suggests that grazing by large herbivores was important in maintaining an open landscape with a mosaic of grassland, scrub and forest (Vera 2000). Modelling by Kirby (2004) has demonstrated that a herbivore-driven dynamic process is able to maintain over extended periods of time intimate mixtures of closed canopy and open wood-pasture at the scale of a few hundred metres. Such a mixture has been observed in the present study, with the northern and southwestern parts of the study site being wood-pasture with persistent large complex gaps and the central to eastern part mainly high, closed canopy where gap creation and closure appear balanced. Thus, as figure 8 shows, the study site can be considered to be mosaic of zones within which disturbance and regeneration [FIGURE 8]

The long-term maintenance of a mosaic of open and closed canopy areas has been demonstrated by Palmer et al. (2004) using field evidence. In temperate oak forest it was shown that grazing by large herbivores had a strong influence on regeneration in some parts of the study sites but little influence on regeneration in areas of dense mature tree canopy, where light availability and soil resources are limiting 
411

412

413

414

415

416

417

418

419

420

421

422

423

424

425

426

427

428

429

430

431

432

433

434

435

436

437

438

439

440

441

442

443

444

factors. The local variations in canopy structure and gap dynamics at the present study site appear to support the concept that temperate broadleaved deciduous forests are a composed of a mixture open and closed canopy areas. Consequently, it is possible to conceive of a mechanism which initiates and sustains a mosaic of different disturbance and regeneration regimes. Within a small geographical area, such as that covered by the study site, which has limited topographic variation, it is unlikely that there will be large spatial variations in tree growth rate (i.e. access to resources) or disturbance rate which can create a mosaic in which there are zones with very different disturbance and regeneration regimes within close proximity. Instead, it may be that subtle environmental variations (e.g. in soil or hydrological conditions) initially create spatial variations in tree productivity and viability which in turn affects susceptibility to disturbance. Thus, for example, certain areas of the forest may contain less robust, shallow rooted trees which are more likely to be felled by lower magnitude but higher frequency storms. This increases the likelihood that gaps will be created within these areas. A process of positive feedback can then continue to differentiate spatial zones within the forest. Where tree growth is more successful, the zone may be less favourable to grazers (particularly large herbivores) due to restricted accessibility and limited ground forage, and a dense closed canopy reduces the susceptibility of individual trees to windthrow. In these zones tree death results in spatially-discrete gaps which are quickly filled by lateral crown growth or regenerating trees which are subjected to reduced grazing intensity. Where tree growth and viability is more limited, the zone may be more favourable to grazers particularly due to more extensive understorey and ground layers, meaning that grazing becomes spatially-focussed within these zones. The suppression of regenerating tree seedlings and the increased susceptibility to windthrow around gap edges or of isolated trees sustains an open tree matrix structure in these zones. Thus the development or maintenance of a disturbance and regeneration 'regime mosaic' depends upon the characteristics of the component zones and the juxtaposition of zones with different regimes within the mosaic.

Greater evidence is now required in order to substantiate the mosaic model proposed above. In addition to further understanding the mechanisms which initiate and sustain different disturbance and regeneration regimes, it is important that we investigate the interactions between zones with different regimes. Interesting questions arise concerning what factors may influence the dominance of one regime over the other and their relative expansion and contraction over time; what size of forest area is required in order to support an interacting mosaic of different regimes; and, how are dynamics of the forest mosaic influenced by adjacent vegetation or landuse types. As recognised by Kuuluvainen \& Aakala (2011) in the context of boreal forest, there is a lack of evidence concerning forest disturbance and regeneration dynamics across a range of spatial scales, with most evidence coming from small survey plots. The present study has highlighted the importance of placing our understanding of local scale dynamics within a wider landscape context, because survey plots would not be large enough to capture the spatial extent of 
the mosaic of disturbance and regeneration regimes that was found in this research. The results confirmed that LiDAR data are valuable for mapping canopy gaps and monitoring long term dynamics in a spatially-

447 comprehensive manner over a large area; this would be virtually impossible using field techniques. The

448 time span covered by available LiDAR data is currently restricted and such data cannot replace long-term

449 repeat surveys of permanent forest plots. Nevertheless, the growing availability of multi-temporal LiDAR

450 datasets presents an important opportunity to provide a spatio-temporal framework for further studies

451 investigating disturbance and regeneration in order to fill gaps in our understanding of these processes

452 within forest ecosystems (see Seidl et al., 2011).

\section{Conclusions}

455 This study aimed to use evidence from temperate broadleaved deciduous forest to determine whether 456 disturbance and regeneration was best described using the recently-developed open matrix model or a 457 traditional model of discrete gap dynamics. By using multi-temporal LiDAR remotely-sensed data we 458 were able to quantify disturbance and regeneration over a 10 year period with fine spatial resolution 459 across a landscape scale. We found that both open matrix and discrete gap dynamics models could be 460 applied but they were each relevant to different zones within a mosaic that was distributed across the 461 landscape. Some zones were dominated by the maintenance and expansion of existing large and complex 462 gaps under a regime of chronic disturbance, resulting in a low tree cover. Several characteristics of the 463 gap and canopy changes indicated that regeneration was restricted and this may be attributable to 464 spatially-focussed grazing by large herbivores within these zones. Other zones contained closed canopy 465 forest, where gap creation and infill were approximately in balance and constrained to discrete spatial 466 units. It is now important to elucidate the abiotic factors and biotic interactions which facilitate the 467 development of such a mosaic and influence its spatio-temporal characteristics within broadleaved 468 deciduous forests and to examine whether such a 'regime mosaic' exists in other forest types.

\section{Acknowledgements}

471 The authors wish to thank the Lancaster Environment Centre, Lancaster University, UK and the Ministry 472 of Higher Education and Universiti Teknologi MARA, Malaysia for their financial support of this project. 473 We also would like to thank the UK Environment Agency and NERC ARSF for providing the LiDAR 474 data. 
References

477 Abd Latif, Z. \& Blackburn, G. A. 2010. The effects of gap size on microclimate and soil water content in 478 a temperate broadleaved deciduous forest. International Journal of Biometeorology 54: 119-129.

479 Arriaga, L. 2000. Gap-building-phase regeneration in a tropical montane cloud forest of north-eastern 480 Mexico. Journal of Tropical Ecology 16: 535-562.

481 Barden, L.S. 1989. Repeatability in forest gap research: studies in the Great Smoky Mountains. Ecology 482 70: 558-559.

483 Barik, S.K., Pandey, H.N., Tripathi, R.S. \& Rao, P. 1992. Microenvironmental variability and species 484 diversity in treefall gaps in a sub-tropical broadleaved forest. Plant Ecology 103: 31-40.

485 Battles, J.J., Dushoff, J.G. \& Fahey, T.J. 1996. Line intersect sampling of forest canopy gaps. Forest 486 Science 42: 131-138.

487 Blackburn, G. A. \& Milton, E. J. 1996. Filling the gaps: remote sensing meets woodland ecology. Global 488 Ecology and Biogeography 5: 175-191.

489 Blackburn, G. A. \& Milton, E. J. 1997. An ecological survey of deciduous woodlands using airborne 490 remote sensing and geographical information systems (GIS). International Journal of Remote Sensing 18: $491 \quad 1919-1935$.

492 Boettcher, S.E. \& Kalisz, P.J. 1990. Single-tree influence on soil properties in the mountains of Eastern 493 Kentucky. Ecology 71: 1365-1372.

494 Boyd, D.S., Hill, R.A., Hopkinson, C. \& Baker, T.R. 2013 Landscape-scale forest disturbance regimes in 495 southern Peruvian Amazonia. Ecological Applications 23: 1588-1602.

496 Bradshaw, R.H.W., Hannon, G.E. \& Lister, A.M. 2003. A long-term perspective on ungulate-vegetation 497 interactions. Forest Ecology and Management 181: 267-280.

498 Brokaw, N.V.L. \& Busing, R.T. 2000. Niche versus chance and tree diversity in forest gaps. Trends in 499 Ecology \& Evolution 15: 183-188.

500 Brokaw, N.V.L. 1982. The definition of treefall gap and its effect on measures of forests dynamics. 501 Biotropica 14: 158-160. 
Brokaw, N.V.L. 1985. Gap phase regeneration in a tropical forest. Ecology 66: 682-687.

503 Canham, C. D. 1988. An index for understory light levels in and around canopy gaps. Ecology 69: 16345041638.

505 Canham, C.D., Denslow, J.S., Platt, W.J., Runkle, J.R., Spies, T.A. \& White, P.S. 1990. Light regimes 506 beneath closed canopies and tree-fall gaps in temperate and tropical forests. Canadian Journal of Forest 507 Research 20: 620-631.

508 Clark, M. L., Clark, D. B. \& Roberts, D. A. 2004. Small foot-print lidar estimation of sub-canopy 509 elevation and tree height in a tropical rain forest landscape. Remote Sensing of Environment 91: 68-89.

510 Dahir, S.E. \& Lorimer, C.G. 1996. Variation in canopy gap formation among developmental stages of 511 northern hardwood stands. Canadian Journal of Forest Research 26: 1875-1892.

512 Denslow, J. \& Spies, T. 1990. Canopy gaps in forest ecosystems: An introduction. Canadian Journal of $513 \quad$ Forest Research 20: 619.

514 Disney, M. I., Kalogirou, V., Lewis, P. E., Prieto-Blanco, A., Hancock, S. \& Pfeifer, M. 2010. Simulating 515 the impact of discrete-return lidar system and survey characteristics over 2 young conifer and broadleaf 516 forests. Remote Sensing Environment 114: 1546-1560.

517 Elias, R. \& Dias, E. 2009. Gap dynamics and regeneration strategies in Juniperus-Laurus forests of the 518 Azores Islands. Plant Ecology 200: 179-189.

519 Falkowski, M.J., Evans, J.S., Martinuzzi, S., Gessler, P.E. \& Hudak, A.T. 2009. Characterizing forest 520 succession with lidar data: An evaluation for the Inland Northwest, USA. Remote Sensing of Environment 521 113: 946-956.

522 Ferreira de Lima, R.A. 2005. Gap size measurement: The proposal of a new field method. Forest Ecology 523 and Management 214: 413-419.

524 Flower, N. 1977. An historical and ecological study of enclosed and unenclosed woods in the New Forest, 525 Hampshire. PhD Thesis, Department of Geography, King's College, University of London, UK.

526 Forestry Commission 2008. Management Plan for the Crown Lands of the New Forest 2008-2013: B4 527 The Ancient \& Ornamental Woodlands. Forestry Commission, Edinburgh, UK.

528 Forestry Commission 2009. Management of Ancient Wood Pasture. Forestry Commission, Edinburgh, 529 UK. 

$550-556$.

Fraver, S., Jonsson, B.G., Jönsson, M., Esseen, P-A. 2008. Demographics and disturbance history of a boreal old-growth Picea abies forest. Journal of Vegetation Science 19: 789-798.

Gagnon, J. L., Jokela, E., Moser, W. K. \& Huber, D. A. 2004. Characteristics of gaps and natural regeneration in mature long-leaf pine flatwoods ecosystems. Forest Ecology \& Management 187: 373537380. and the effects of platform altitude. Remote Sensing of Environment 103: 140-152.

540 Gravel, D., Canham, C.D., Beaudet, M. \& Messier, C. 2010. Shade tolerance, canopy gaps and mechanisms of coexistence of forest trees. Oikos 119: 475-484.

542 Higo, M., Komiyama, A. \& Ninimiya, I. 1992. Growth rate, crown form and leaf arrangement of 543 deciduous broadleaved tree species in Japan. Research Bulletin of the Faculty of Agriculture Gifu 544 University 57: 35-43.

545 Hodgson, M. E. \& Bresnahan, P. 2004. Accuracy of airborne Lidar-derived elevation: Empirical 546 assessment and error budget. Photogrammetric Engineering \& Remote Sensing 70: 331-339.

547 Hodgson, M. E., Jensen, J. R., Schmidt, L., Schill, S. \& Davis, B. 2003. An evaluation of LIDAR- and 548 IFSAR-derived digital elevation models in leaf-on conditions with USGS Level 1 and Level 2 DEMs. 549 Remote Sensing of Environment 84: 295-308.

550 Hyde, P., Dubayah, R., Walker, W., Blair, J. B., Hofton, M. \& Hunsaker, C. 2006. Mapping forest 551 structure for wildlife habitat analysis using multisensor (lidar, SAR/InSAr, ETM+, Quickbird) synergy. 552 Remote Sensing of Environment 102: 63-73.

553 Hytteborn, H. \& Verwijst. T. 2014. Small-scale disturbance and stand structure dynamics in an old554 growth Picea abies forest over 54 yr in central Sweden. Journal of Vegetation Science 25: 100-112.

555 Hu, L., Gong, Z., Li, J. \& Zhu, J. 2009. Estimation of canopy gap size and gap shape using a 556 hemispherical photograph. Trees 23: 1101-1108. 
557 Kathke, S. \& Bruelheide, H. 2010. Interaction of gap age and microsite type for the regeneration of Picea 558 abies. Forest Ecology and Management 259: 1597-1605.

559 Katzenbeisser, R. 2003. About the calibration of lidar sensors. ISPRS Workshop on "3-D Reconstruction 560 form Airborne Laser-Scanner and InSAR data”. 8-10 October 2003, Dresden, Germany.

561 Kirby, K.J. 2004. A model of a natural wooded landscape in Britain as influenced by large herbivore 562 activity. Forestry 77: 405-420.

563 Koukoulas, S. \& Blackburn, G.A. 2004. Quantifying the spatial properties of forest canopy gaps using 564 LiDAR imagery and GIS. International Journal of Remote Sensing 25: 3049-3071.

565 Koukoulas, S. \& Blackburn, G.A. 2005. Spatial relationships between tree species and gap characteristics 566 in broad-leaved deciduous woodland. Journal of Vegetation Science 16: 587-596.

567 Kraus, K. \& Pfeiffer, N. 1998. Determination of terrain models in wooded areas with airborne laser 568 scanner data. Photogrammetric Engineering \& Remote Sensing 53: 193-203.

569 Kuuluvainen, T. \& Aakala, T. 2011. Natural forest dynamics in boreal Fennoscandia: a review and 570 classification. Silva Fennica 45: 823-841.

571 Lefsky, M.A., Cohen, W.B., Parker, G.G. \& Harding, D.J. 2002. Lidar remote sensing for ecosystem 572 studies. BioScience 52: 19-30.

573 Li, Z.Q., Bogaert, J. \& Nijs, I. 2005. Gap pattern and colonization opportunities in plant communities: 574 effects of species richness, mortality, and spatial aggregation. Ecography 28: 777-790.

575 Lieberman,M., Lieberman, D. \& Peralta, R. 1989. Forests are not just Swiss cheese: canopy 576 stereogeometry of non-gaps in tropical forests. Ecology 70: 550-552.

577 Lima, R.A.F. \& Moura, L.C. 2008. Gap disturbance regime and composition in the Atlantic montane rain 578 forest: the influence of topography. Plant Ecology 197: 239-53.

579 Liu, Q. \& Hytteborn, H. 1991. Gap structure, disturbance and regeneration in a primeval Picea abies 580 forest. Journal of Vegetation Science 2: 391-402.

581 Marthews, T.R., Burslem, D.F.R.P., Paton, S.R., Yanyuez, F. \& Mullins, C.E. 2008. Soil drying in a 582 tropical forest: three distinct environments controlled by gap size. Ecological Modelling 216: 369-384. 
McCarthy, J. 2001. Gap dynamics of forest trees: With particular attention to boreal forests.

584 Environmental Reviews 9: 1-59.

585 Mitchell, F.J.G. 2005. How open were European primeval forests? Hypothesis testing using 586 palaeoecological data. Journal of Ecology 93: 168-177.

587 Morgan, R.K. 1987. Composition, structure and regeneration characteristics of the open woodlands of the 588 New Forest, Hampshire. Journal of Biogeography 14: 423-428.

589 Mountford, E.P. \& Peterken, G.E. 2003. Long-term change and implications for the management of wood 590 pastures: experience over 40 years from Denny Wood, New Forest. Forestry 76: 19-43.

591 Mountford, E.P., Savill, P.S. \& Bebber, D.P. 2006. Patterns of regeneration and ground vegetation 592 associated with canopy gaps in a managed beechwood in southern England. Forestry 79: 389-408.

593 Muscolo, A., Sidari, M. \& Mercurio, R. 2007. Influence of gap size on organic matter decomposition, 594 microbial biomass and nutrient cycle in Calabrian pine (Pinus laricio, Poiret) stands. Forest Ecology and 595 Management 242: 412-418.

596 Naesset, E. 2004. Effects of different flying altitudes on biophysical stand properties estimated from 597 canopy height and density measured with a small foot-print airborne scanner. Remote Sensing of 598 Environment 91: 243-255.

599 NERC ARSF 2012. Natural Environment Research Council Airborne Research and Survey Facility. 600 http://arsf.nerc.ac.uk/ [Natural Environment Research Council]

601 Palmer, S.C.F., Mitchell, R.J., Truscott, A.-M. \& Welch, D. 2004. Regeneration failure in Atlantic 602 oakwoods: the roles of ungulate grazing and invertebrates. Forest Ecology and Management 192: 251603265.

604 Pickett, S.T.A. \& White, P.S. 1985. The ecology of natural disturbance and patch dynamics. Academic 605 press, New York, USA.

606 Ritter, E., Dalsgaard, L. \& Einhorn, K. S. 2005. Light, temperature and soil moisture regimes following 607 gap formation in a semi-natural beech-dominated forest in Denmark. Forest Ecology and Management 608 206: 15-33.

609 Runkle, J.R. 1982. Patterns of disturbance in some old-growth mesic forests of Eastern North America. 610 Ecology 63: 1533-1546. 
611 Sapkota, I.P. \& Oden, P.C. 2009. Gap characteristics and their effects on regeneration, dominance and

612 early growth of woody species. Journal of Plant Ecology 2: 21-29.

613 Schliemann, S.A. \& Bockheim, J.G. 2011. Methods of studying treefall gaps: A review. Forest Ecology 614 and Management 261: 1143-1151.

615 Schnitzer, S.A. \& Carson, W.P. 2001. Treefall gaps and the maintenance of species diversity in a tropical 616 forest. Ecology 82, 913-919.

617 Seidl, R., Fernandes, P.M., Fonseca, T.F., Gillet, F., Jönsson, A.M., Merganicová, K., Netherer, S., 618 Arpaci, A., Bontemps, J-D, Bugmann, H., González-Olabarria, J.R., Lasch, P., Meredieu, C., Moreira, F., 619 Schelhaas, M-J. \& Mohren, F. 2011. Modelling natural disturbances in forest ecosystems: a review. 620 Ecological Modelling 222: 903-924.

621 Spies, T.A., Franklin, J.F. \& Klopsch, M. 1990. Canopy gaps in Douglas-fir forests of the Cascade 622 Mountains. Canadian Journal of Forest Research 20: 649-658.

623 Stewart, G.H., Rose, A.B. \& Veblen, T.T. 1991. Forest development in canopy gaps in old-growth beech 624 (Nothofagus) forests, New Zealand. Journal of Vegetation Science 2: 679-690.

625 St-Onge, B., Jumelet, J., Cobello, M. \& Véga, C. 2004. Measuring individual tree height using a 626 combination of stereophotogrammetry and lidar. Canadian Journal of Forest Research 34: 2122-2130.

627 St-Onge, B. \& Vepakomma, U. 2004. Assessing forest gap dynamics and growth using multi-temporal 628 laser-scanner data. Proceedings of the Laser-Scanners for Forest and Landscape Assessment -

629 Instruments, Processing Methods and Applications International Conference. Frieburg im Breisgau, 3-6

630 Octobre 2004, p173-178.

631 Tanaka, H. \& Nakashizuka, T. 1997. Fifteen years of canopy gap dynamics analysed by aerial 632 photographs in a temperate deciduous forest, Japan. Ecology 78: 612-620.

633 Tanentzap, A.J., Bazely, D.R., Koh, S., Timciska, M, Haggith, E.G., Carleton, T.J. \& Coomes, D.A.

634 2011. Seeing the forest for the deer: Do reductions in deer-disturbance lead to forest recovery? Biological 635 Conservation 144: 376-382.

636 Taylor, A.H. \& Qin, Z. 1988. Regeneration patterns in old-growth Abies-Betula forests in the Wolong 637 Natural Reserve, Sichuan, China. Journal of Ecology 76: 1204-1218. 
638

639

640

641

642

643

644

645

646

647

648

649

650

651

652

653

654

655

656

657

658

659

660

661

662 determination of forest growth using airborne laser scanning. Remote Sensing of Environment 90: 451-

663462.

Torimaru, T., Itaya, A. \& Yamamoto, S-I. 2012. Quantification of repeated gap formation events and their spatial patterns in three types of old-growth forests: Analysis of long-term canopy dynamics using aerial photographs and digital surface models. Forest Ecology and Management 284: 1-11.

Tubbs, C.R. 1986. The New Forest: A natural history. Collins, London, UK.

Ulanova, N.G. 1991. Vegetation mapping as a tool for detection of windfall processes in primary forest communities. Phytocoenosis 3, 219-222.

Ulanova, N.G. 2000. The effects of windthrow on forests at different spatial scales: a review. Forest Ecology and Management 135: 155-167.

Van Dam, O. 2001. Forest filled with gaps: Effects of gap size on water and nutrient cycling in tropical rain forest. A study in Guyana. PhD Thesis. Uthrect University, Netherlands.

Veblen, T.T. 1989. Tree regeneration responses to gaps along a transandean gradient. Ecology 70: 541543.

Vepakomma, U., St-Onge, B. \& Kneeshaw, D. 2008. Spatially explicit characterization of boreal forest gap dynamics using multi-temporal lidar data. Remote Sensing of Environment 112: 2326-2340.

Vepakomma, U., St-Onge, B. \& Kneeshaw, D. 2011. Response of a Boreal forest to canopy opening: assessing vertical and lateral tree growth with multi-temporal lidar data. Ecological Applications 21: 99121.

Vera, F.W.M. 2000. Grazing Ecology and Forest History. CABI Publishing, Wallingford, UK.

Vetaas, O.R. 1997. The effect of canopy disturbance on species richness in a central Himalayan oak forest. Plant Ecology 132: 29-38.

White, P.S. 1979. Pattern, process, and natural disturbance in vegetation. Botanical review 45: 229-299.

Yang, J., Ge, J., Liu, L., Ding, Y. \& Tan, Y. 2009. Gap phase regeneration recruitment of mixed coniferbroadleaf forests in Wolong Nature Reserve. Frontiers of Forestry in China 4: 153-158.

Yu, X., Hyypae, J., Kaartinen, H. \& Maltamo, M. 2004. Automatic detection of harvested trees and 462. 
664 Zang, R.G., Tao, J.P. \& Li, C.Y. 2005. Within community patch dynamics in a tropical montane rain 665 forest of Hainan Island, South China. Acta Oecologia 28: 39-48. 
Table 1. Specifications of the two LiDAR instruments used for data acquisition.

\begin{tabular}{lrr}
\hline Specification & 1997 & 2007 \\
\hline Model of Optech LiDAR & ALTM 1020 & ALTM 3033 \\
Flight altitude (m AGL) & 730 & 1000 \\
Divergence (mrad) & 0.3 & 0.23 \\
Pulse frequency (Hz) & 5000 & 33,333 \\
Max. scan angle (degrees) & 20 & 20 \\
Point density (hits $\left./ \mathrm{m}^{2}\right)$ & 0.3 & 1 \\
\hline
\end{tabular}


Table 2. Descriptive statistics for canopy gaps in 1997 and 2007.

\begin{tabular}{lrr}
\hline Statistics & 1997 & 2007 \\
\hline Total study area $\left(\mathrm{m}^{2}\right)$ & 1009488 & 1009488 \\
Max canopy height $(\mathrm{m})$ & 31.3 & 32.0 \\
Number of gaps & 905 & 989 \\
Total gap area $\left(\mathrm{m}^{2}\right)$ & 211044 & 237096 \\
Percent of total area & 20.9 & 23.5 \\
covered by gaps $(\%)$ & 4077 & 8369 \\
Mean gap area $\left(\mathrm{m}^{2}\right)$ & 23372 & 40252 \\
Max gap area $\left(\mathrm{m}^{2}\right)$ & 1390 & 3107 \\
Mean perimeter $(\mathrm{m})$ & 7884 & 14716 \\
Max perimeter $(\mathrm{m})$ & 0.47 & 0.49 \\
Mean P:A & 2.00 & 2.00 \\
Max P:A & 0.17 & 0.20 \\
Min P:A & & \\
\hline
\end{tabular}


Table 3. Gap dynamics expressed using the area involved in various types of change during the study period. Minimum area recorded for all changes was $1 \mathrm{~m}^{2}$ i.e. the spatial resolution of the canopy height model. The numbers of gaps experiencing the various types of change are not mutually exclusive, as any single gap can experience more than one type of change.

\begin{tabular}{|c|c|c|}
\hline \multicolumn{3}{|c|}{ Gap gain } \\
\hline $\begin{array}{c}\text { Area of } \\
\text { entirely new } \\
\text { gaps }\end{array}$ & $\begin{array}{c}\text { Area of } \\
\text { expansion } \\
\text { from existing } \\
\text { gaps }\end{array}$ & $\begin{array}{c}\text { Total gap } \\
\text { area gained }\end{array}$ \\
\hline
\end{tabular}

gaps

\begin{tabular}{lccc}
\hline Total area $\left(\mathrm{m}^{2}\right)$ & 10328 & 79116 & 89444 \\
\hline Max area $\left(\mathrm{m}^{2}\right)$ & 404 & 532 & 532 \\
\hline Mean area $\left(\mathrm{m}^{2}\right)$ & 79.5 & 74.5 & 75.0 \\
\hline $\begin{array}{l}\text { No. of gaps } \\
\text { experiencing this } \\
\text { change }\end{array}$ & 238 & 780 & N/A \\
\hline
\end{tabular}

\begin{tabular}{ccccccc}
\hline \multicolumn{7}{c}{ Gap loss } \\
\hline Area of entire gap closure & Area of contraction from existing gaps & $\begin{array}{c}\text { Total } \\
\text { gap } \\
\text { area lost }\end{array}$ \\
\hline $\begin{array}{c}\text { Due to } \\
\text { lateral } \\
\text { crown } \\
\text { expansion }\end{array}$ & $\begin{array}{c}\text { Due to } \\
\text { regeneration } \\
\text { / vertical } \\
\text { growth }\end{array}$ & $\begin{array}{c}\text { Total area } \\
\text { of closure }\end{array}$ & $\begin{array}{c}\text { Due to } \\
\text { lateral } \\
\text { crown } \\
\text { expansion }\end{array}$ & $\begin{array}{c}\text { Due to } \\
\text { regeneration } ~ \\
\text { vertical } \\
\text { growth }\end{array}$ & $\begin{array}{c}\text { Total area } \\
\text { of } \\
\text { contraction }\end{array}$ & \\
\hline 2380 & 2312 & 4692 & 35504 & 23196 & 58700 & 63392 \\
\hline 68 & 108 & 216 & 128 & 96 & 296 & 296 \\
\hline 19.1 & 22.8 & 54.8 & 16.6 & 11.8 & 36.5 & 37.9 \\
\hline 116 & 124 & 133 & 704 & 640 & 734 & N/A \\
\hline
\end{tabular}




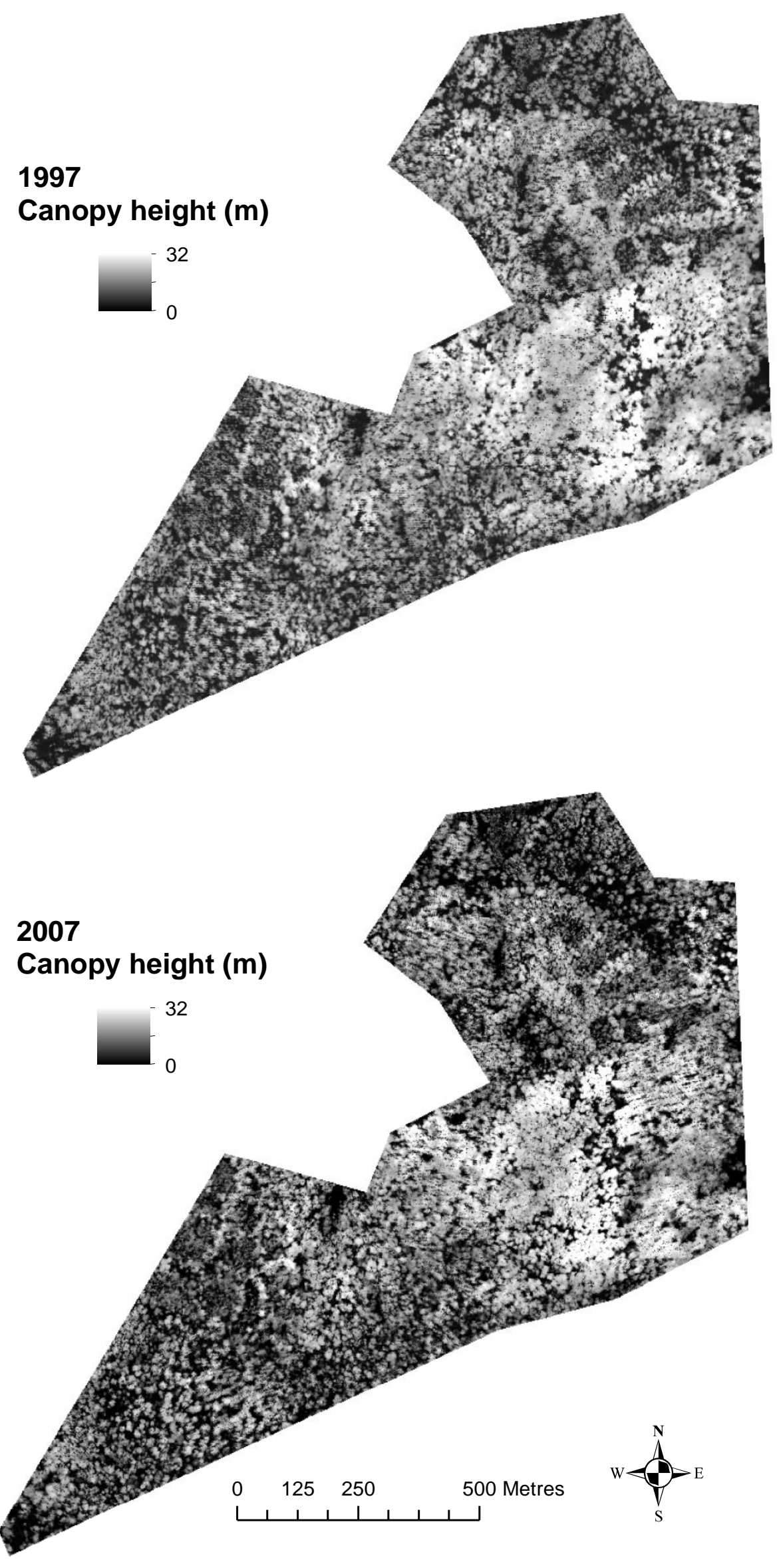

Figure 1. Canopy height models of the study area for 1997 and 2007 derived using LiDAR data. 


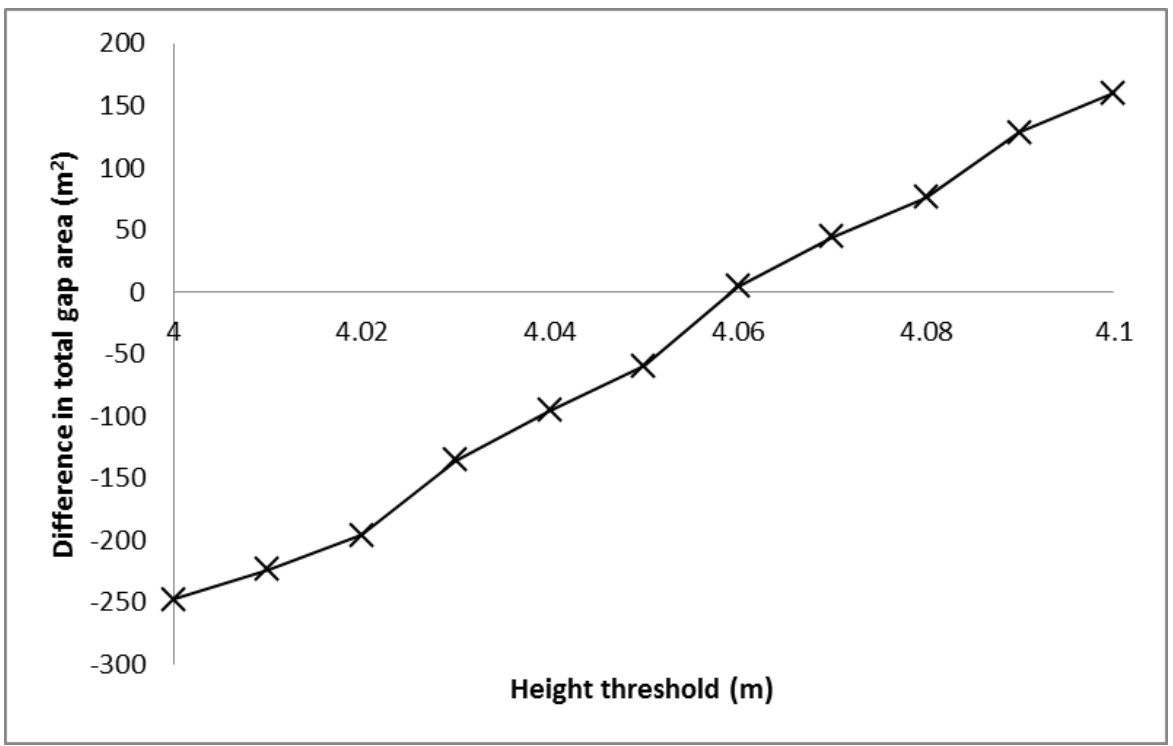

Figure 2. Difference in total gap area delineated between the original 2007 canopy height model and the reduced point density canopy height model when applying different height thresholds to the reduced point density canopy height model for gap delineation. 


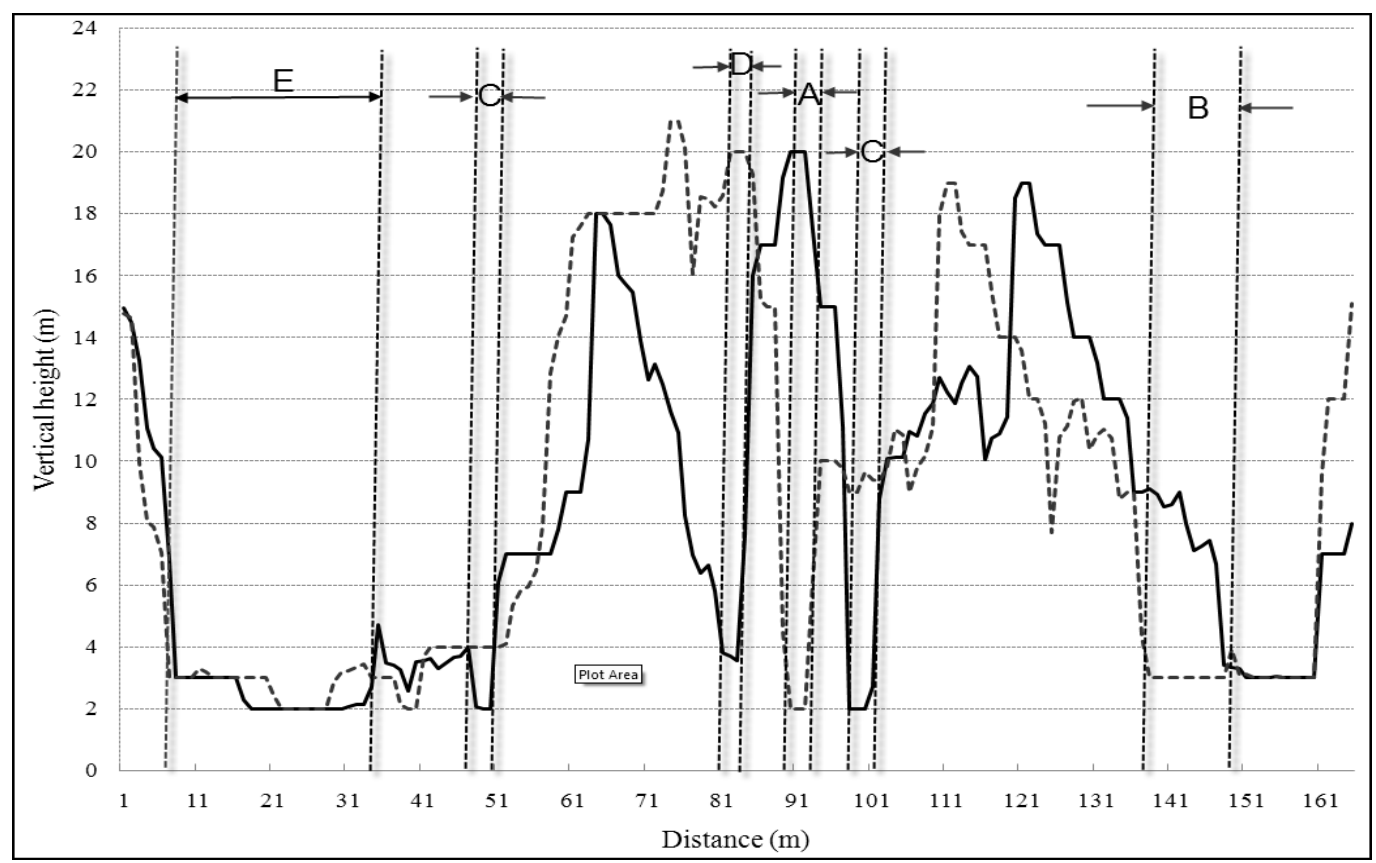

Figure 3. Canopy height models showing vertical profile changes between 1997 (bold line) and 2007 (dashed line). (A) new gap; (B) gap expansion; (C) gap closure from below due to regeneration; (D) gap closure due to lateral expansion of tree crowns; (E) a continuous gap area, existing in 1997 and 2007. 


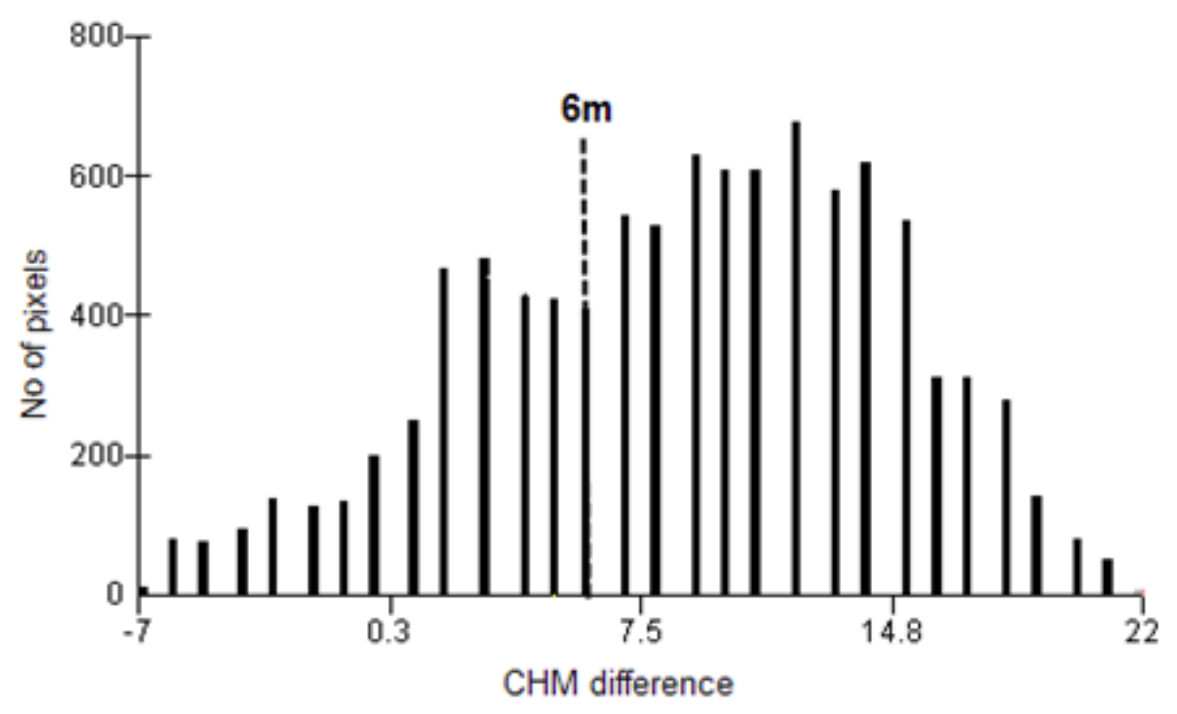

Figure 4. Histogram showing the difference between the canopy height models from 1997 and 2007. A threshold of $6 \mathrm{~m}$ was identified using natural breaks algorithm in ArcGIS, to distinguish between height increments due to regeneration and those due to lateral crown expansion. 


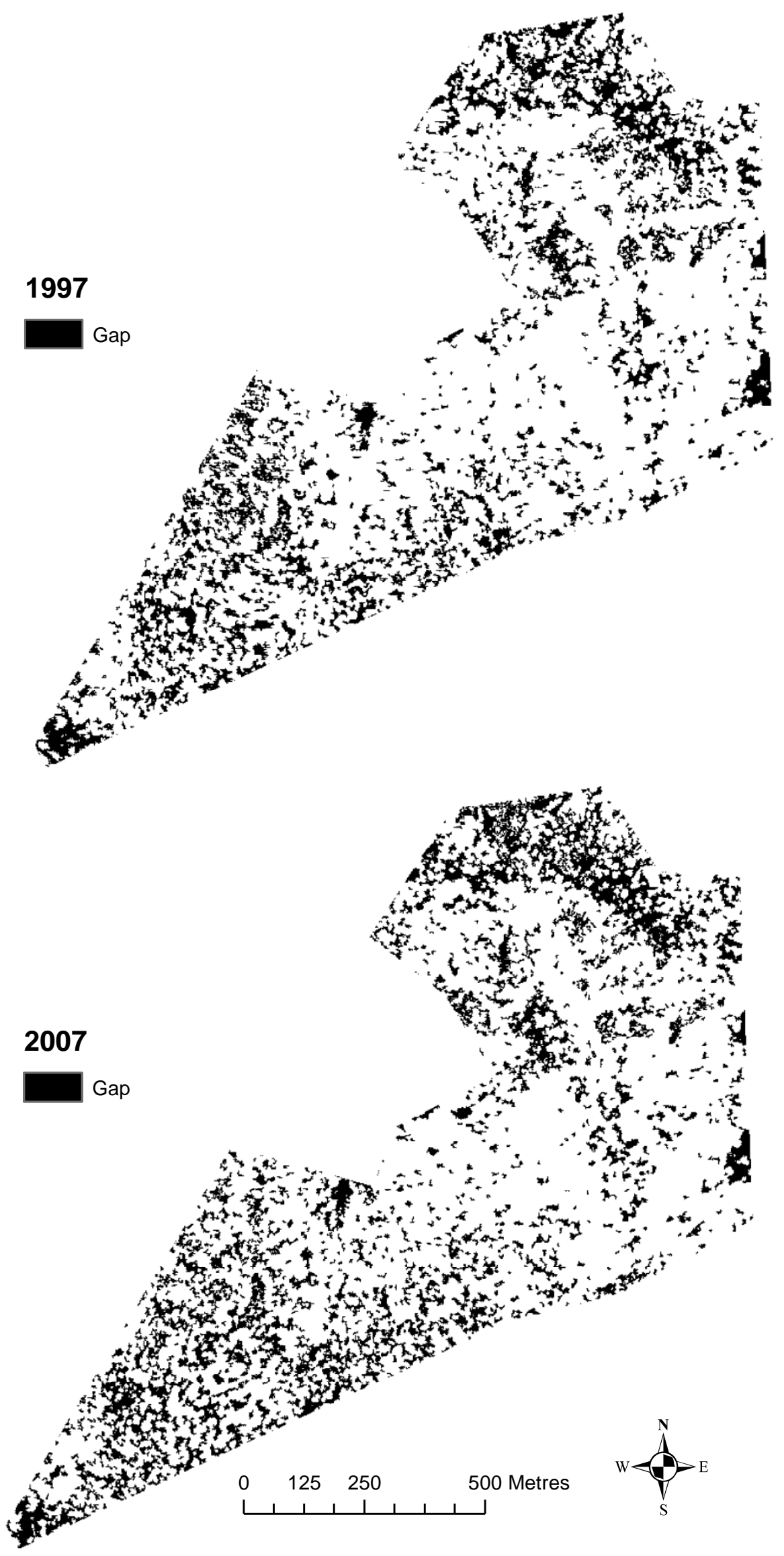

Figure 5. Distribution of canopy gaps in the study area in 1997 and 2007. 


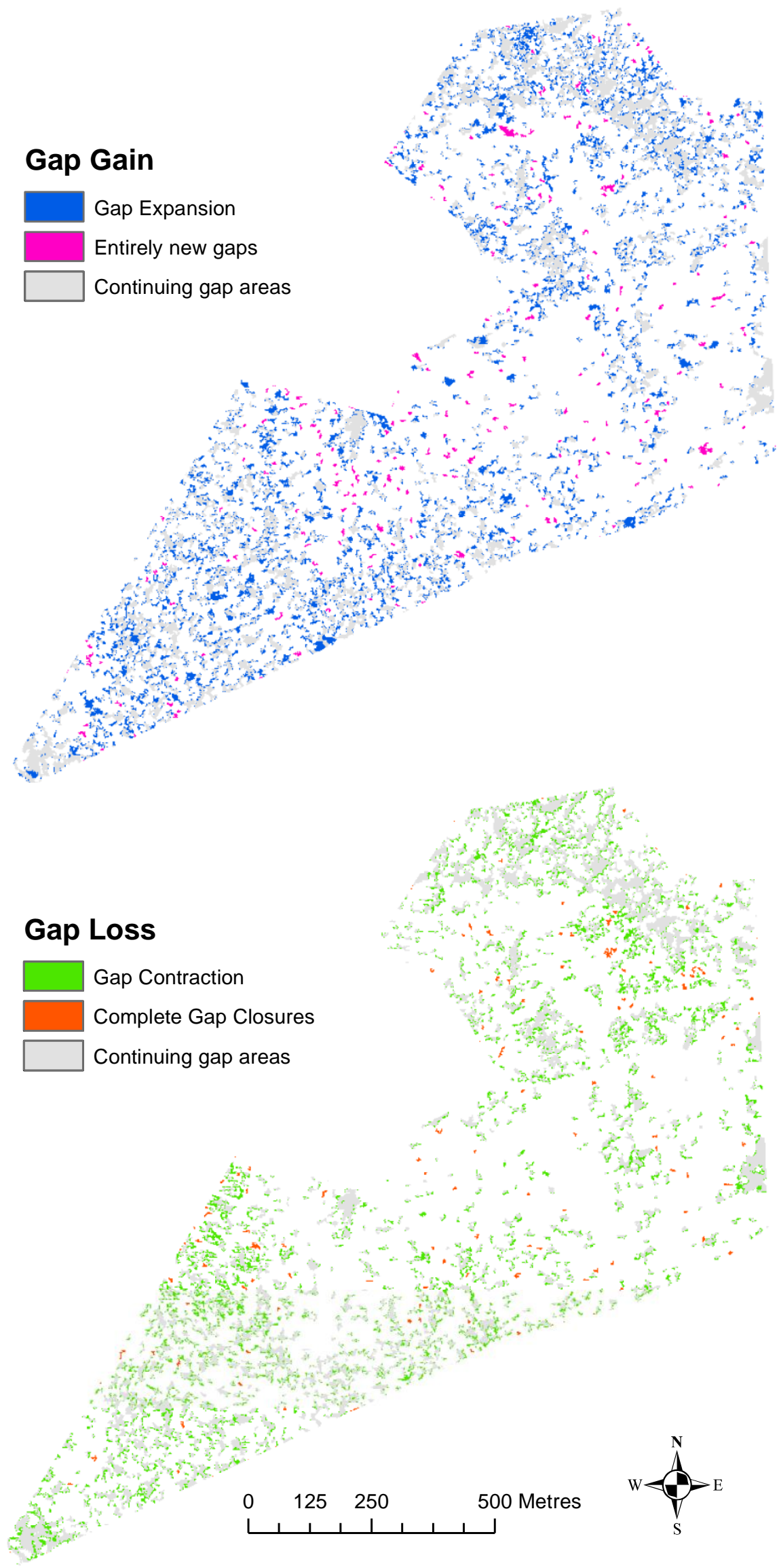

Figure 6. Spatial representations of loss and gain in gap areas between 1997 and 2007. 


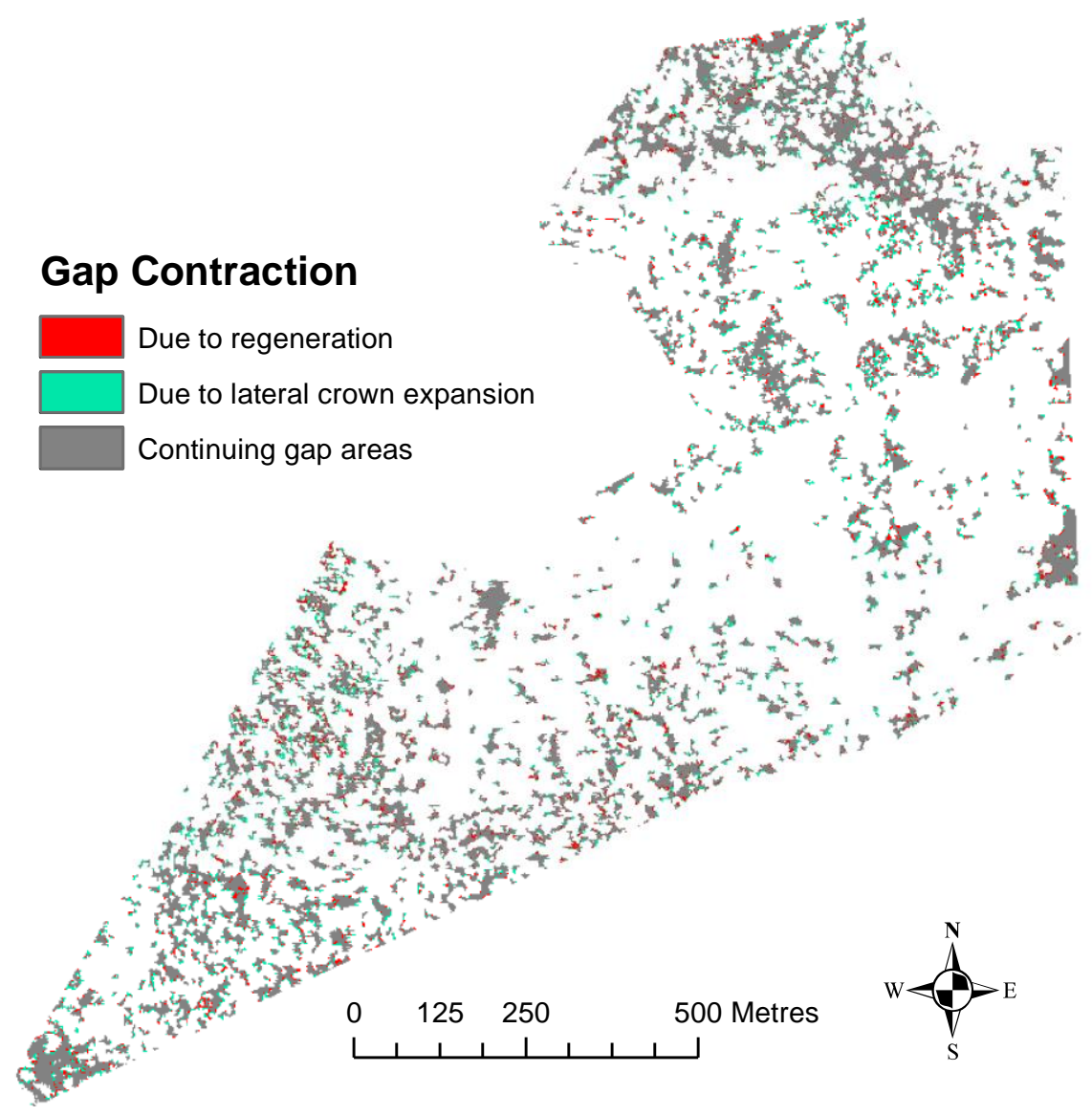

Figure 7. Gap areas that have contracted due to regeneration and lateral crown expansion. 


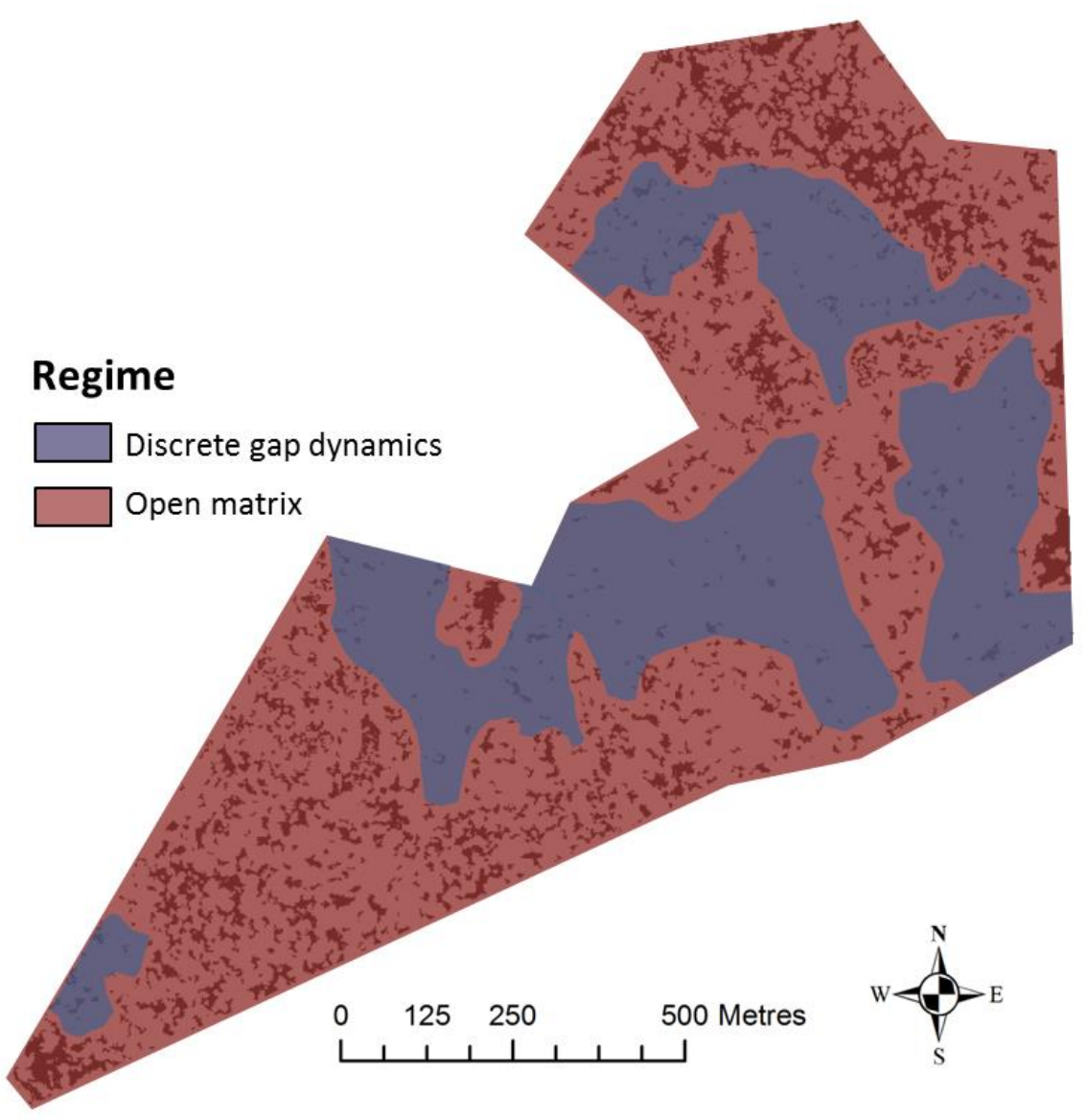

Figure 8. The mosaic of different disturbance and regeneration regimes. Zones have been delineated by applying a series of spatial filters to the map of continuing gap areas (which is shown beneath the regimes map). 

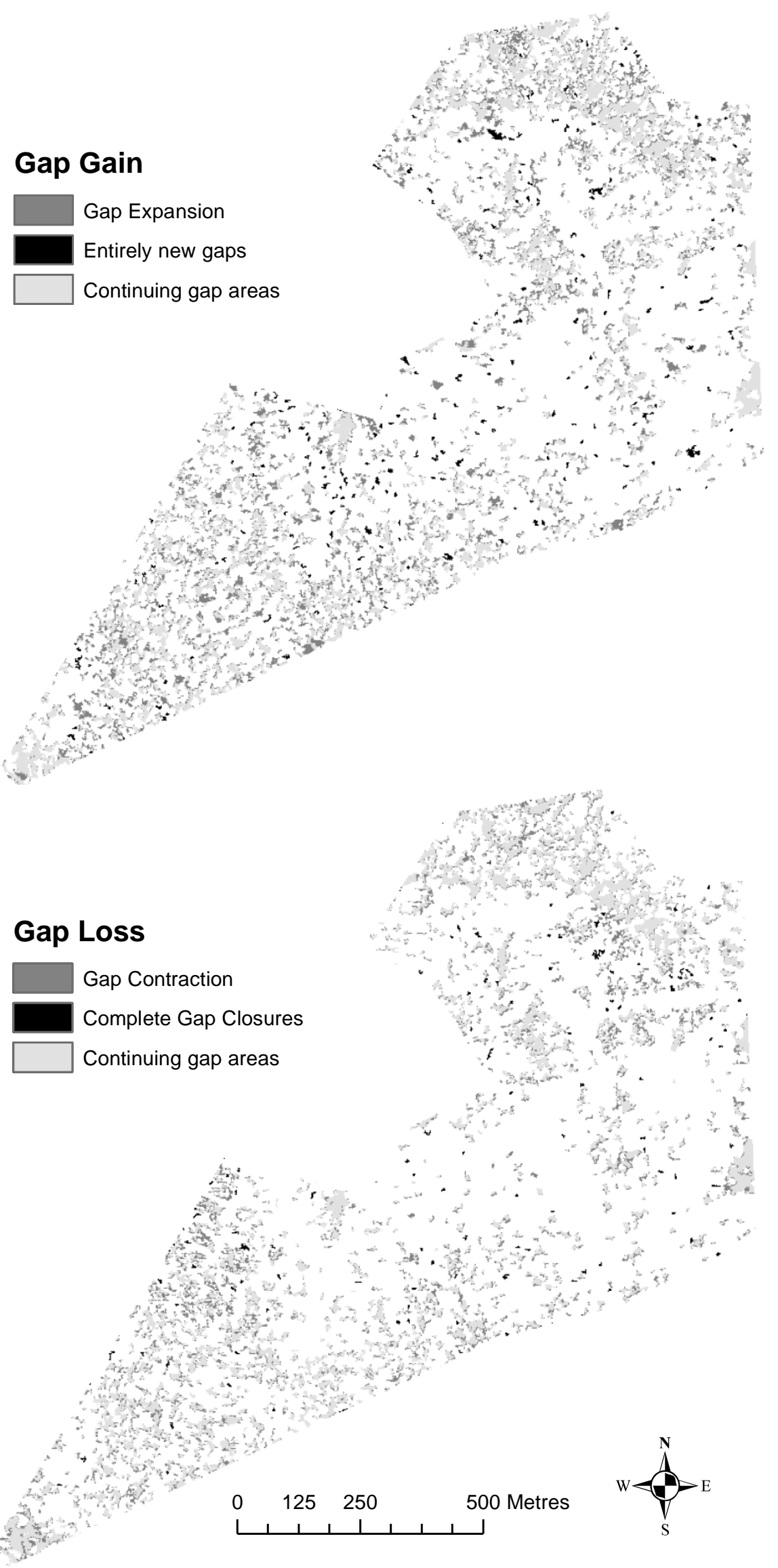

Figure 6. Spatial representations of loss and gain in gap areas between 1997 and 2007. 


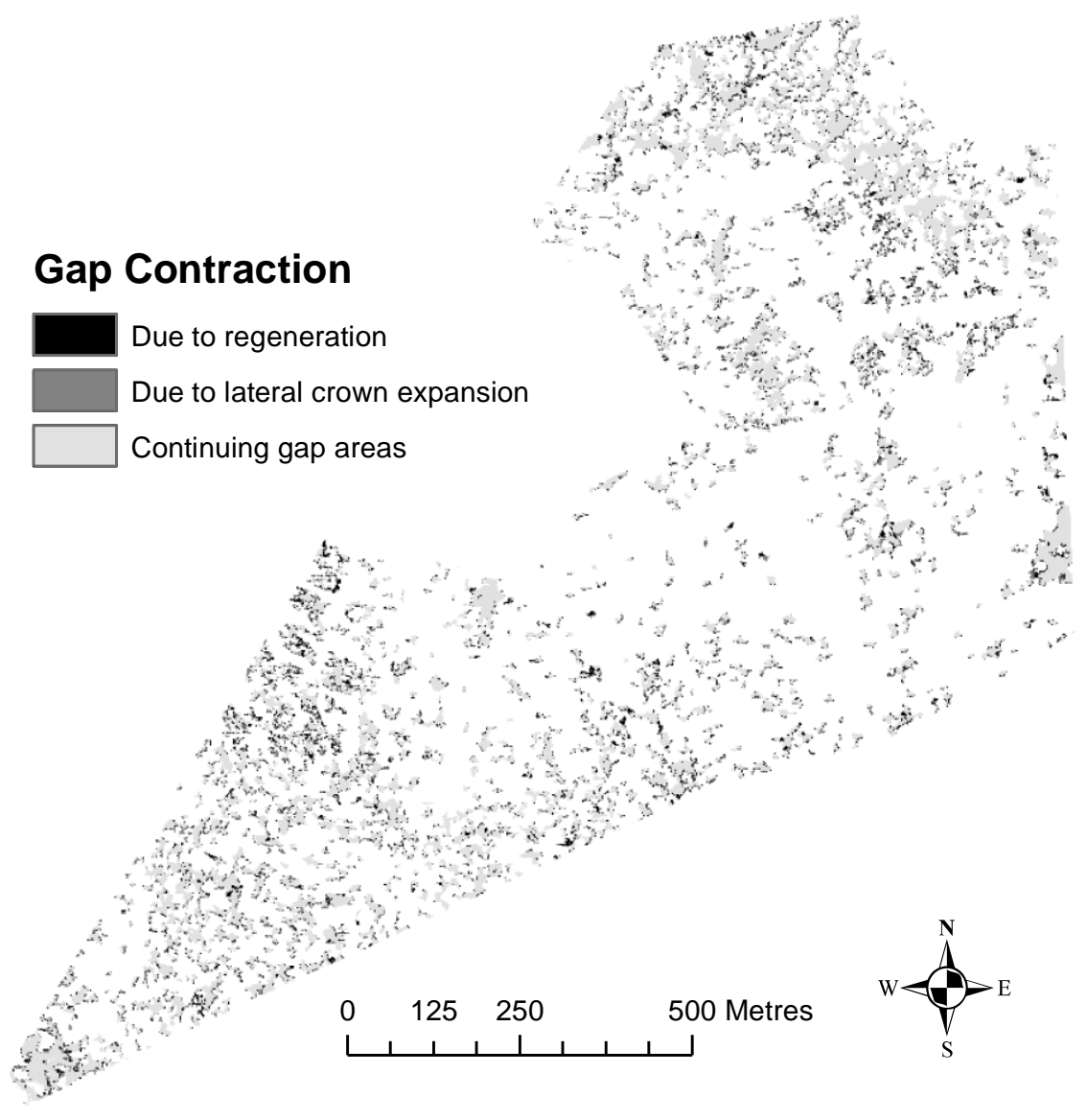

Figure 7. Gap areas that have contracted due to regeneration and lateral crown expansion. 


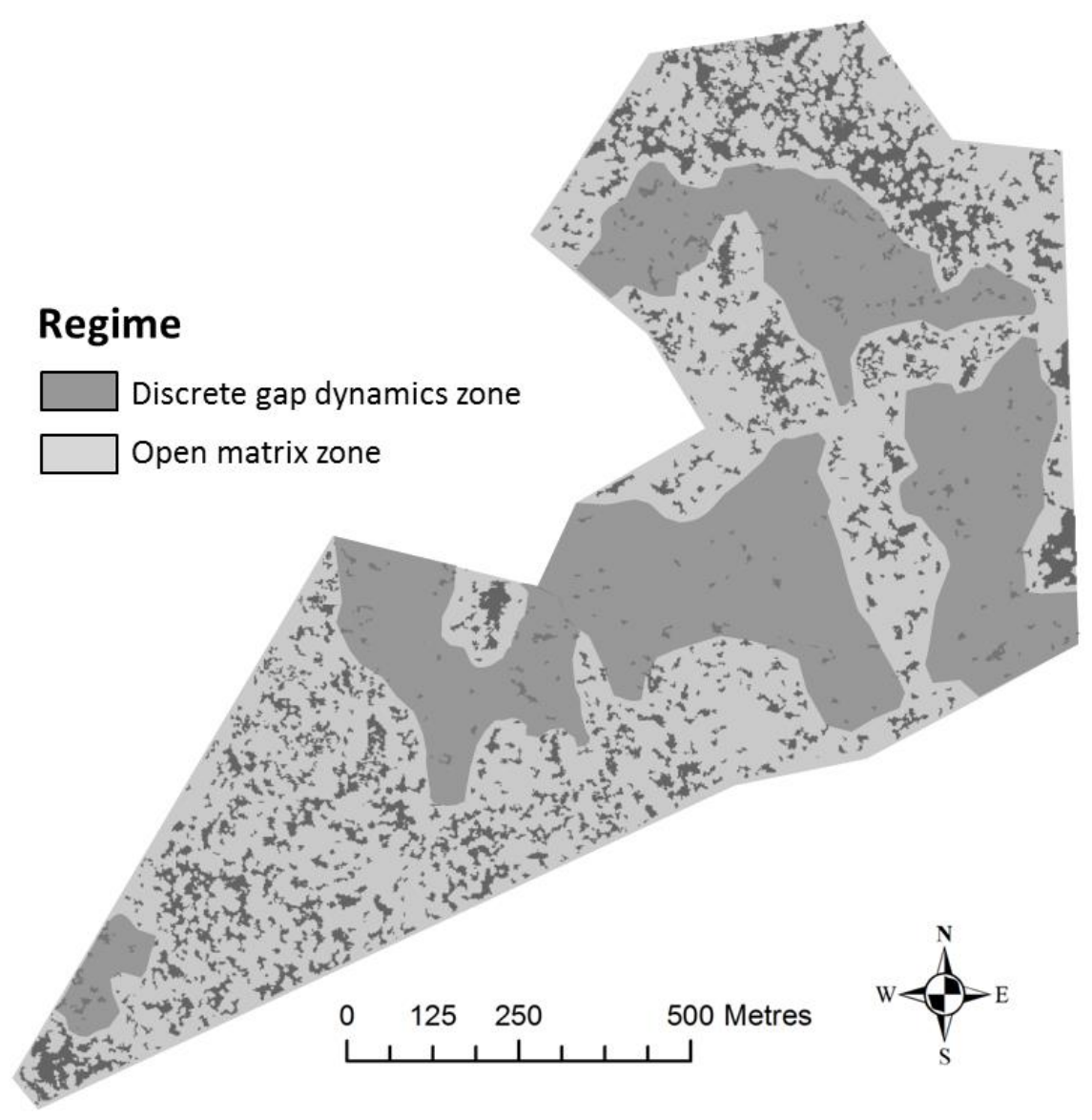

Figure 8. The mosaic of different disturbance and regeneration regimes. Zones have been delineated by applying a series of spatial filters to the map of continuing gap areas (which is shown beneath the regimes map). 